Esquivel Sánchez, F.J., Alarcón Moreno, L., Esquivel Guerrero, J.A. y Fernández García M.I. (2019): “Caracterización estadística y registro de la terra sigillata hispánica a partir de restos de un vertedero del alfar romano de Isturgi (Los Villares de Andújar, Jaén)", Spal 28.1: 173-192. DOI: http://dx.doi.org/10.12795/spal.2019.i28.08

\title{
CARACTERIZACIÓN ESTADÍSTICA Y REGISTRO DE LA TERRA SIGILLATA HISPÁNICA A PARTIR DE RESTOS DE UN VERTEDERO DEL ALFAR ROMANO DE ISTVRGI (LOS VILLARES DE ANDÚJAR, JAÉN) QUALITATIVE AND QUANTITATIVE CHARACTERIZATION OF THE HISPANIC TERRA SIGILLATA FROM THE ISTVRGI'S POTTERY COMPLEX (LOS VILLARES DE ANDUJAR, JAÉN).
}

\author{
FRANCISCO JAVIER ESQUIVEL SÁNCHEZ \\ Departamento de Estadística e Investigación Operativa. Universidad de Granada. \\ Avenida de Fuente Nueva, s\n. 18071, Granada. Correo-e: jesquivel@ugr.es. (D) https://orcid.org/0000-0001-8296-1013 \\ LAURA ALARCÓN MORENO \\ Departamento de Prehistoria y Arqueología. Universidad de Granada \\ Calle Profesor Clavera, s/n. 18011, Granada. Correo-e: lauraperiana@correo.ugr.es. (ID) https://orcid.org/0000-0003-2748-9718 \\ JOSÉ ANTONIO ESQUIVEL GUERRERO \\ Departamento de Prehistoria y Arqueología. Universidad de Granada \\ Calle Profesor Clavera, s/n. 18011, Granada. Correo-e: esquivel@ugr.es. (D) https://orcid.org/0000-0002-4525-7489 \\ MARÍA ISABEL FERNÁNDEZ GARCÍA \\ Departamento de Prehistoria y Arqueología. Universidad de Granada \\ Calle Profesor Clavera, s/n, c.p.: 18011, Granada. Correo-e: mifernan@ugr.es. (D) https://orcid.org/0000-0003-3030-346X
}

\begin{abstract}
Resumen: El centro de producción de terra sigillata hispánica vinculado a la antigua ciudad de Isturgi (Los Villares de Andújar, Jaén) ha sido objeto de investigación arqueológica desde los años 70, generando aportaciones a la comunidad científica nacional e internacional que han convertido el yacimiento en un importante referente. Con el objetivo de caracterizar la terra sigillata hispánica, se toma una muestra representativa de piezas provenientes de un vertedero del barrio artesanal de Isturgi, las cuales son registradas mediante un completo sistema de fichas y analizadas utilizando herramientas estadísticas de descripción, contraste de hipótesis, clasificación y estudio de su diversidad morfológica, usando remuestreo Jackknife para estimar índices estadísticos. Los resultados muestran una fuerte asociación entre las versiones, lisas y decoradas, de esta clase cerámica y la funcionalidad de las piezas con sus dimensiones físicas. De aquí se puede intuir un alto de grado especialización en las piezas cerámicas, respecto a la función para la que estaban destinadas. Respecto a la diversidad morfológica, se ha cuantificado que existía mayor diversidad de formas de piezas lisas, sin que unas formas fuesen más utilizadas. Por el contrario, las piezas decoradas presentan un menor grado de diversidad y, en este caso, había formas más utilizadas.
\end{abstract}

Abstract: The Hispanic terra sigillata production center linked to the ancient city of Isturgi (Los Villares de Andújar, Jaén) has been subject to continuous archaeological research since the 1970s, providing significant contributions to the national and international scientific. For characterizing the Hispanic terra sigillata, it has been selected a representative random sample of pieces, which are registered by means of a complete system of registration forms and analyzed using statistical tools of description, hypothesis tests, classification and study of their morphological diversity using Jackknife to estimate statistical indicators. The results obtained show a strong association between the decorated and non-decorated versions of the ceramic class and the functionality of the pieces with their physical dimensions. From this, it could be interpreted as that the production of the ceramics pieces reached a high degree of specialization according with the function for which they were intended. Regarding the morphological diversity of both versions, it has been quantified that there was a greater diversity of forms within the non-decorated pieces with no forms being more used than the others. Conversely, the forms of the decorated pieces present a lower degree of diversity but, in this case, some forms were more predominantly used than others. 
Palabras clave: Baetica, contraste de hipótesis, indicadores de diversidad, Isturgi, Jackknife, técnicas de clasificación estadística, terra sigillata hispánica.

\section{INTRODUCCIÓN}

La producción y el comercio de manufacturas han mostrado ser fuentes de información muy importantes para explicar la estructura de sociedades antiguas. En el estudio del pasado romano de la península ibérica, la terra sigillata proveniente del complejo alfarero isturgitano ha permitido establecer una importante secuencia cronotipológica, a partir de la cual se ha podido profundizar en sus estructuras de producción y comercialización (Fernández-García 2012, 2013b, 2013c, 2015). El estudio continuado del yacimiento de Isturgi, desde su descubrimiento hasta la actualidad, con tres grandes proyectos de investigación, ha colocado a este entre los centros productores de terra sigillata hispánica más destacables de la península ibérica. Recientes estudios han mostrado cómo aplicaciones estadísticas permiten analizar grandes cantidades de datos con diversas variables, por lo que se propone un estudio cuantitativo y cualitativo frente a un estudio cualitativo basado en la mera observación (Esquivel et al. 1991; Orton 1982; Shennan 1992). Conviene no olvidar que los materiales arqueológicos aportan una serie de variables tanto categóricas como métricas que, valoradas en conjunto, pueden ayudar de forma efectiva a establecer diferencias y semejanzas en el material arqueológico. En concreto, en el ámbito del estudio de la cerámica, la estadística ha sido especialmente relevante en el análisis tipológico, pues pretende explicar empíricamente las características de diversidad de tipologías cerámicas (Fernández de Marcos García et al. 2017; Kaufman 1998; Orton y Tyers 1990; Orton y Hughes 2013). En este trabajo los principales objetivos que se plantean son el registro y divulgación de la cerámica isturgitana, a través de un registro exhaustivo mediante un sistema de fichas, y la caracterización de las piezas cerámicas en cuanto a su clase, forma, función y dimensiones físicas, mediante la aplicación de técnicas estadísticas como herramientas de clasificación, contraste de hipótesis o índices de diversidad.

En la siguiente sección se resumen las principales singularidades de la ciudad de Isturgi, entre las que destacan la importancia de este yacimiento como centro
Key Words: Baetica, hypothesis test, diversity indicators, Isturgi, Jackknife, statistical classification techniques, hispanic terra sigillata.

alfarero en época romana y el alto grado de conocimiento de este, fruto del trabajo de investigación continuado durante más de cuatro décadas. En este trabajo se trata de caracterizar la terra sigillata mediante el estudio estadístico y el registro de una muestra aleatoria representativa de fragmentos cerámicos proveniente del complejo alfarero isturgitano. Las descripciones de la muestra seleccionada y de las fichas de registro construidas se introducen en la sección 3. En la sección 4 se presenta un completo estudio estadístico. En primer lugar, se analiza la distribución de frecuencias con base en las principales características cualitativas de clasificación de las piezas, que son su clase cerámica, su forma y la función para la que estaban destinadas. Además se realiza un estudio de asociación entre el uso y las versiones lisas o decoradas de las piezas. Posteriormente, se realiza una clasificación de las piezas atendiendo a la única variable métrica disponible en un número significativo de ellas, el diámetro de la boca, y se compara con las clasificaciones a partir de la clase de cerámica y la función de las mismas. Para terminar de caracterizar las piezas se realiza un análisis de diversidad tipológica de las diferentes formas, distinguiendo entre decoradas y lisas mediante la estimación de los indicadores de Menhinick y Shannon-Weaver utilizando la técnica de remuestreo Jackknife. En la última sección se resume brevemente el trabajo, realizando una discusión de los principales resultados y señalando futuras líneas de trabajo abiertas a partir de este.

\section{NOTAS ACERCA DEL BARRIO ARTESANAL DE ISTVRGI}

La antigua ciudad de Isturgi (Los Villares de Andújar) contaba entre sus actividades económicas con un importante barrio artesanal dedicado, aparte de otras funciones, a la producción de diversas clases cerámicas. Una amplia variación de manufacturas se constata en época preflavia, entre las que destacan las producciones de tipo Peñaflor, pintada de tradición ibérica, de paredes finas, común, de imitación de barniz interno rojo pompeyano, lucernas, pesas de telar y productos en 


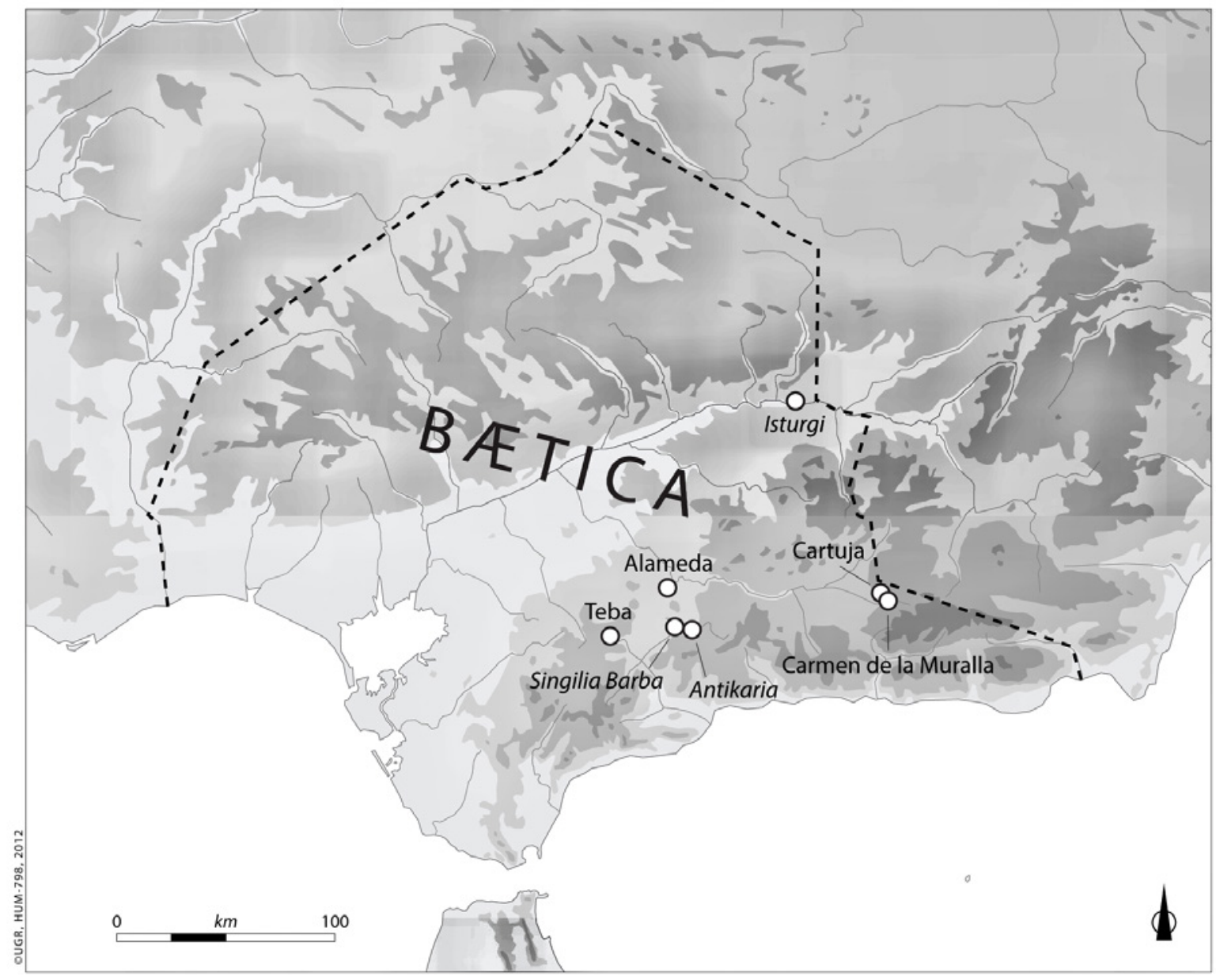

Figura 1. Alfares productores de terra sigillata hispánica de la Baetica.

terra sigillata hispánica (actualizadas todas las producciones en la monografía de Fernández-García 2013a: 155-318). Estos últimos, cuando aparecen desbancan a las restantes clases cerámicas en cuanto a volumen de producción y comercialización se refiere. En la actualidad, el complejo alfarero isturgitano (fig. 1) se ha convertido en un claro referente en relación con las manufacturas en terra sigillata hispánica, no solo por el establecimiento de una importante cronotipología de producción que permite su aplicación en los centros receptores consumidores de sus manufacturas, sino también porque ha permitido profundizar en el estudio de sus estructuras de producción y comercialización, con lo que ello implica a nivel de reconstrucción de la historia social y económica de esta parte de la Baetica. Ello ha sido posible porque, desde que fue dado a conocer el yacimiento (Sotomayor 1973), nunca se ha dejado de investigar en el lugar. A lo largo de la historia de la investigación del yacimiento, se han desarrollado tres grandes proyectos de investigación: "Romanización del Alto Guadalquivir" (I.P. Sotomayor Muro 19711979 y M. Roca Roumens 1979-1989), “Isturgi romana y su territorio: la producción de terra sigillata y su difusión (I.P. Ma I. Fernández García 1995-2011) y "Proyecto Isturgi: Otro indigenismo y otra romanización: la configuración del artesanado romano y de los fenómenos productivos en las áreas periféricas del Alto Guadalquivir” (I.P. M I I. Fernández García 2012-activo).

Del complejo isturgitano conocemos una parte importante del funcionamiento de sus estructuras de producción, durante las tres generaciones de alfareros productores de terra sigillata hispánica establecidas en el yacimiento, que se corresponden con época preflavia, flavia y fines del siglo I/siglo II (Fernández-García 


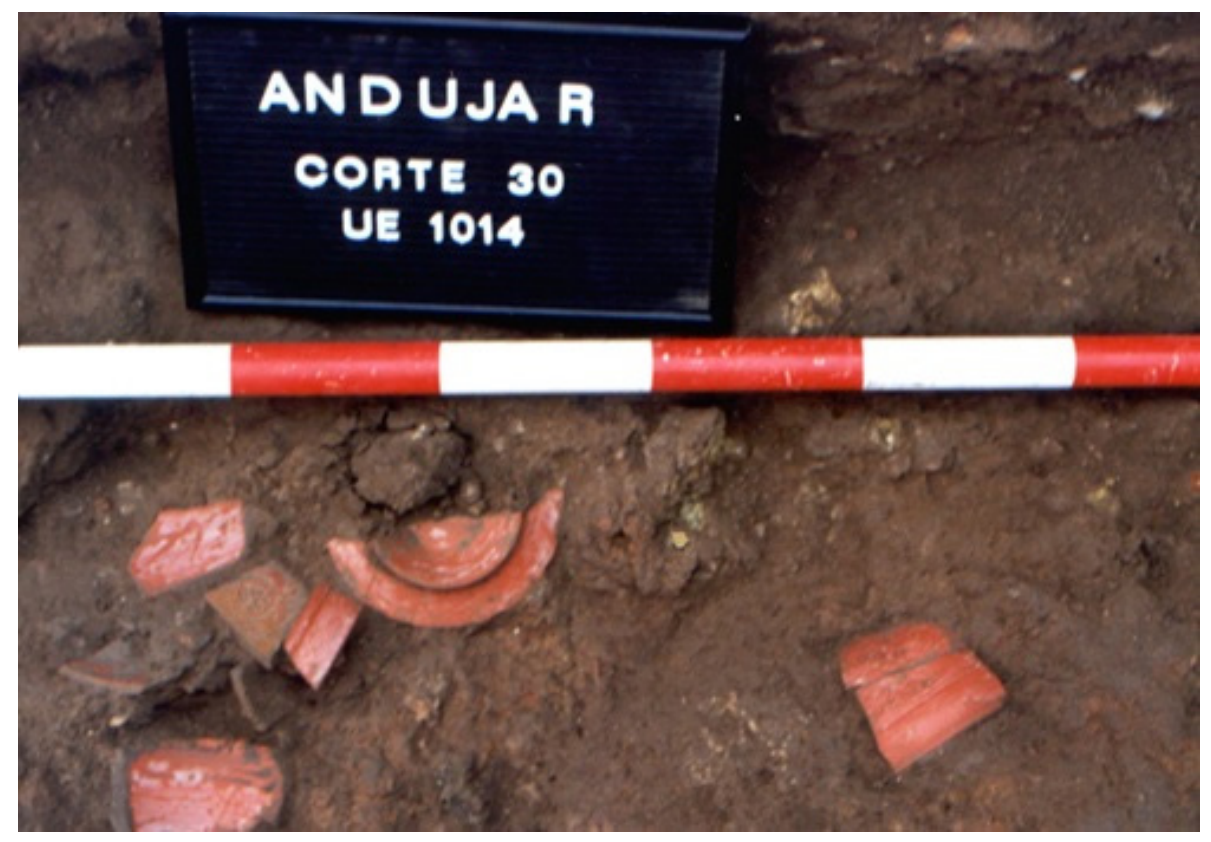

Figura 2. Detalle vertedero campaña 1999. Los Villares de Andújar.

2013b). En este sentido, de sus estructuras físicas de producción destacan sobremanera los potentes vertederos excavados, que tan solo representan una mínima parte de la producción. Igualmente se ha recuperado una parte de la zona de combustión, de la que se han exhumado durante los procesos de excavación cinco hornos a los que se suman otros dos localizados en procesos de prospección. Son estructuras fornaceas de planta circular, con la parrilla sostenida por un pilar central cuya estructura nos remite al mundo indígena. Asimismo, se han localizado las canteras de arcilla destinadas a la elaboración de las diversas cerámicas (Fernández-García 2013c: 69-71; Ruiz-Montes 2013: 75-90). Por otra parte, las estructuras humanas de producción nos acercan a unas officinae que dejan constancia de su trabajo mediante marcas de carácter epigráfico o anepígrafico (Fernández-García 2012: 384-387), enmarcadas dentro de unas incipientes y rudimentarias estructuras económicas de producción materializadas por las denominadas probinas (Fernández-García y Macías-Fernández 2013a: 109-128).

El amplio volumen de producción generado por el complejo isturgitano necesitaba de una importante planificación de sus estructuras de comercialización que le permitiera la distribución de las manufacturas. En todo el proceso comercial intervienen una serie de elementos sin los cuales estas no habrían sido posibles. En este sentido, los caminos derivados de un ramal de la vía Augustea y la propia vía fluvial, con el Baetis navegable desde el propio alfar mediante barcazas hasta Corduba y de ahí hasta el océano, permitían el acceso de los diferentes productos a los mercados a corta, media y larga distancia. En este recorrido cobran importancia los centros redistribuidores de las manufacturas. Igualmente las "sucursales" dependientes al menos en sus inicios de los alfares isturgitanos; y todo ello, en perfecta conjunción, posibilitaba la llegada a los centros receptores de sus productos cerámicos. Estos viajaban con otros productos básicos tales como vino, aceite, $g a$ rum u otros artículos de primera necesidad (FernándezGarcía 2015: 58-62).

\section{MATERIALES Y MÉTODOS}

Para el presente estudio se ha utilizado una serie de ejemplares cerámicos de terra sigilla hispánica, procedentes de las actuaciones contempladas dentro del proyecto de investigación denominado "Proyecto Isturgi romana y su territorio: la producción de terra sigillata y su difusión” dirigido por $\mathrm{M}^{\mathrm{a}}$ Isabel Fernández García (1995-2011). Es importante señalar que los fragmentos fueron localizados en un vertedero (fig. 2), adscrito a época preflavia y flavia, por lo que nos encontramos ante productos de desecho debido a alguna imperfección decorativa, a unas malas condiciones de hornada e incluso a un posible desgaste en el caso de algunos moldes. Debido a esto, de todo el material exhumado 
tan solo en muy pocos casos se han conservado los recipientes completos o, en su defecto, con una porción significativa de superficie útil intacta. En concreto, los fragmentos objeto de estudio han sido seleccionados del material recuperado en la campaña de excavación realizada en 1999, dejando al margen aquellos en los que la adscripción formal plantea algún tipo de duda, amorfos. En total se han analizado 118 fragmentos cerámicos. Con propósito divulgativo y para tener un acceso completo y remoto de cada una de las piezas, se elaboró un sistema exhaustivo de registro. A través del software File Maker Pro Advanced 12 se crearon una serie de fichas donde se describen formalmente los ejemplares cerámicos (ver fig. 3). En estas fichas quedan registradas las principales características cualitativas y cuantitativas que identifican a cada ejemplar cerámico.

Características cualitativas: Para estas variables cabe destacar que no se tienen datos faltantes y que estas características son comparables.

- Localización hace referencia al lugar donde se han encontrado estos ejemplares, en este caso todas las piezas pertenecen al yacimiento de Isturgi.

- Sigla es la clave de identificación individual de la pieza cerámica que hace referencia al yacimiento, unidad estratigráfica y número de pieza dentro de ese estrato

- Corte hace referencia a la división del yacimiento.

- Clase es el tipo de producción cerámico, en nuestro caso distinguimos en terra sigillata lisa y decorada.

- Atendiendo a la morfología de las piezas se pueden establecer diferentes formas. En el caso de que el nombre de la forma comience por Aj. seguido de un dígito significa que son propias del yacimiento de Isturgi. Se ha establecido una tipología abierta al objeto de incorporar posibles nuevos tipos.

- Función se refiere al uso para el que estaba destinada la pieza. Para realizar esta clasificación nos encontramos con el problema de la imposibilidad de aplicar técnicas de análisis de residuos, debido a que proceden de vertederos y, por tanto, se trata de desechos de producción no aptos para la comercialización. Por tanto, atendiendo a las características morfológicas de las piezas y, con las debidas reservas, hemos distinguido entre líquidos (piezas cuya función era contener productos líquidos), sólidos (piezas cuya función era contener productos sólidos) y tapaderas.

- Por pasta se entiende la materia prima transformada por el proceso de cocción. La clasificación de esta es un criterio muy tradicional en el que es usual seguir el code de couleurs des sols (Cailleux, 1981).
- Se utiliza el término de barniz, aceptado unánimemente por los especialistas, aun siendo consciente de tratarse de un engobe sintetizado (Roca Roumens y Fernández-García 1999: 267)

- En decoración se describen formalmente los elementos iconográficos que aparecen en los ejemplares cerámicos.

- Para tener una imagen visual se incorpora una fotografía y un dibujo siguiendo los protocolos al uso.

Características cuantitativas: Estas variables pueden presentar problemas tanto de comparabilidad como de datos faltantes. El problema surge cuando se trabaja con piezas que son fragmentos aleatorios del objeto original. En este caso nos encontramos con mediciones no comparables, que no dependen del objeto original sino de la fractura que sufrió (por ejemplo, peso o altura conservada), y con datos faltantes por ser valores dimensionales de partes no conservadas por la pieza bajo estudio (por ejemplo, altura total o diámetro de la boca).

- Diámetro de la boca es la anchura de la boca del ejemplar cerámico. Esta característica es comparable entre las piezas que tengan esta medición. Hay que destacar que muchas de las piezas bajo estudio conservan la boca. Por tanto, el gran número de piezas con esta característica junto con el hecho de que esta es comparable permite extraer significativa información mediante la aplicación de técnicas estadísticas.

- Diámetro del pie es la anchura máxima del círculo que compone el pie de las piezas cerámicas. Esta medida es comparable pero presenta un gran número de datos faltantes.

- Altura total es la distancia vertical desde la base del objeto cerámico hasta el borde de la boca. Esta medida es comparable pero presenta un gran número de datos faltantes.

- Altura conservada es la distancia vertical de la pieza conservada. Esta medida no es comparable. Esta medida no presenta datos faltantes pero no es comparable, por lo que no permite la aplicación de técnicas estadísticas.

- Altura del pie es la medida vertical del pie de la pieza conservada. Esta medida no presenta datos faltantes pero no es comparable, por lo que no permite la aplicación de técnicas estadísticas.

- Peso de la pieza medido en gramos. Este no presenta datos faltantes pero no es comparable, por lo que no permite la aplicación de técnicas estadísticas. 


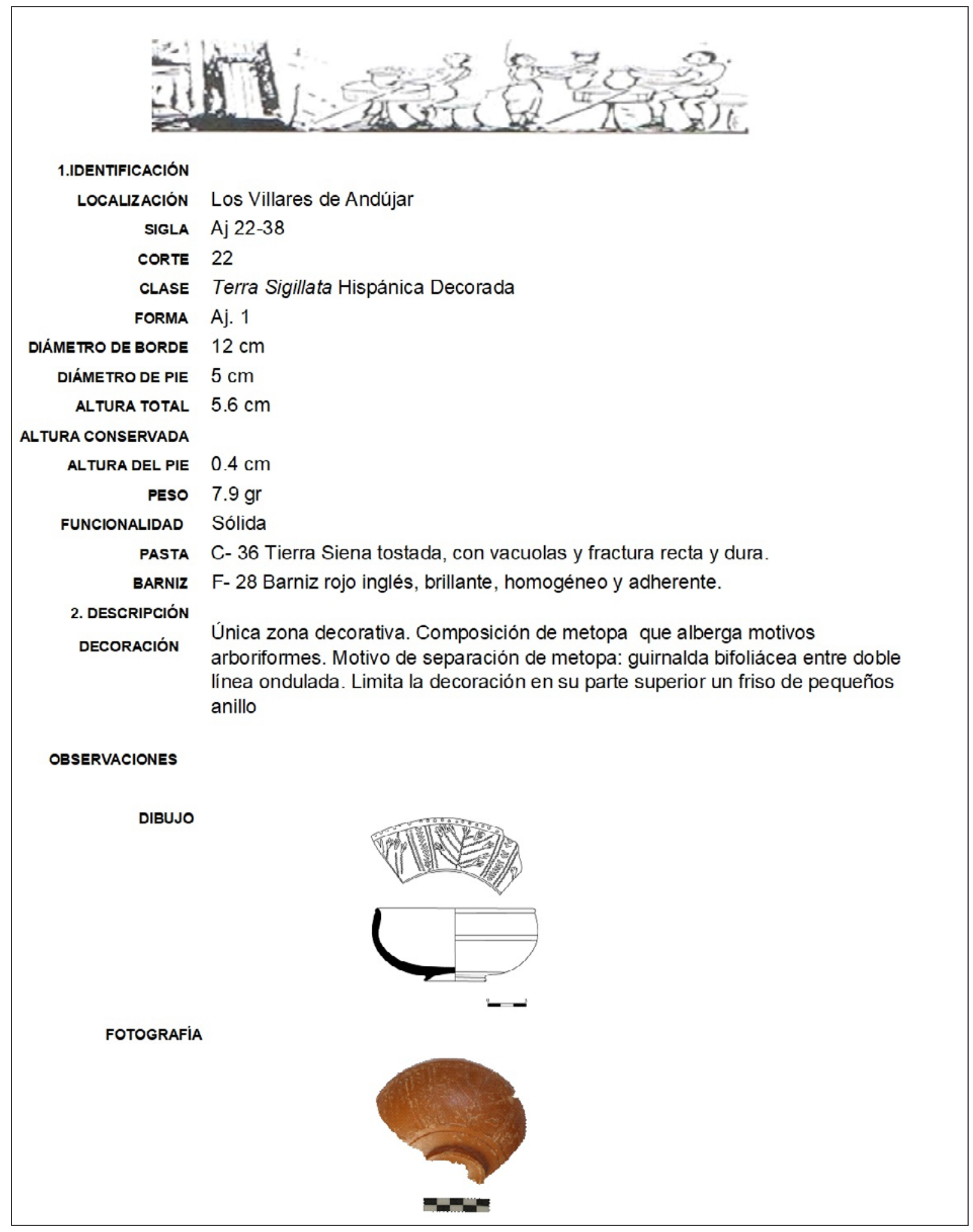

Figura 3. Ejemplo de ficha de registro. 


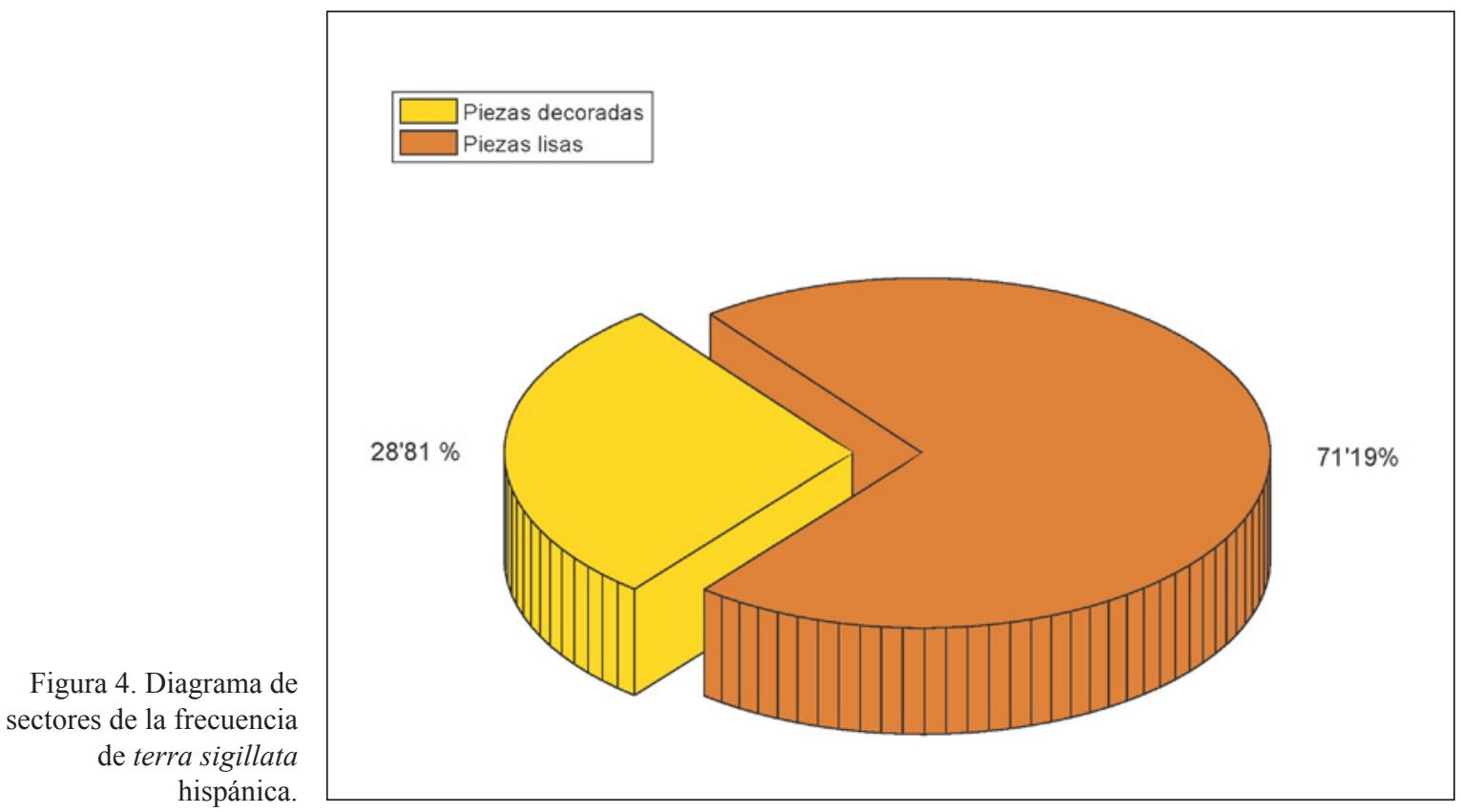

\section{ESTUDIO ESTADÍSTICO}

En esta sección se presentan los diferentes análisis estadísticos realizados para caracterizar las piezas cerámicas de terra sigillata isturgitana. En primer lugar, se estudia la distribución de frecuencias de las principales características cualitativas de clasificación de las piezas: la clase, la tipología y la función de las piezas. Posteriormente se realiza una clasificación de las piezas a partir de la única variable dimensional común en un número considerablemente alto del total de piezas estudiadas, el diámetro de la boca, y se compara con la clasificación obtenida atendiendo a la clase y la función de las piezas. Por último, mostramos un estudio de diversidad tipológica de las piezas decoradas frente a las lisas mediante los indicadores de Menhinick y Shannon-Weaver, calculados aplicando la técnica de remuestreo Jackknife que nos permite estimar el error de estimación y, por tanto, la realización de intervalos de confianza y contrastes de hipótesis. En este trabajo todas las metodologías utilizadas se han implementado en el lenguaje de programación Matlab.

\subsection{Análisis de las distribuciones de frecuencias}

Los ejemplares de terra sigillata hispánica se clasifican principalmente en dos categorías atendiendo a si las cerámicas están decoradas o no (fig. 4). Estos resultados indican un dominio de la terra sigillata lisa $(71,19 \%)$ frente a la terra sigillata decorada, con un $28,81 \%$. Esta diferencia porcentual puede deberse a que las piezas de terra sigillata lisa pueden ser producidas fácilmente por cualquier officina debido a la menor dificultad de su elaboración. Por el contrario, para la fabricación de los ejemplares decorados se necesita una mayor complejidad estructural, al ser necesarios tres estadios productivos: los fabricantes de punzones, de moldes y de vasos decorados. No todas las officinae pueden disponer de esos artesanos especializados que hacen posible los productos ornamentados. Esto explica, por tanto, su menor volumen de producción en relación con la terra sigillata lisa, la cual conjuga una elaboración sencilla con un mayor volumen en un límite temporal muy reducido, lo que redunda en una altísima rentabilidad económica para las officinae que la producen. Además, el menor coste de las cerámicas lisas junto con su mayor agilidad en su elaboración podría también justificar su preponderancia frente a los ejemplares decorados.

En cada uno de estos dos tipos cerámicos hemos podido identificar una serie de formas. En el caso de la terra sigillata decorada hemos distinguido seis diferentes, dentro del total de las elaboradas en el alfar (Fernández-García y Moreno-Alcaide 2013); su distribución de frecuencias se muestra en la fig. 5 y la tab. 1 . A partir de su distribución se observa la preponderancia de la 37 con $50 \%$ de las piezas totales, seguida de la 29 $(17,6 \%)$ y de la Aj. 1 (14,7\%). También cabe destacar 


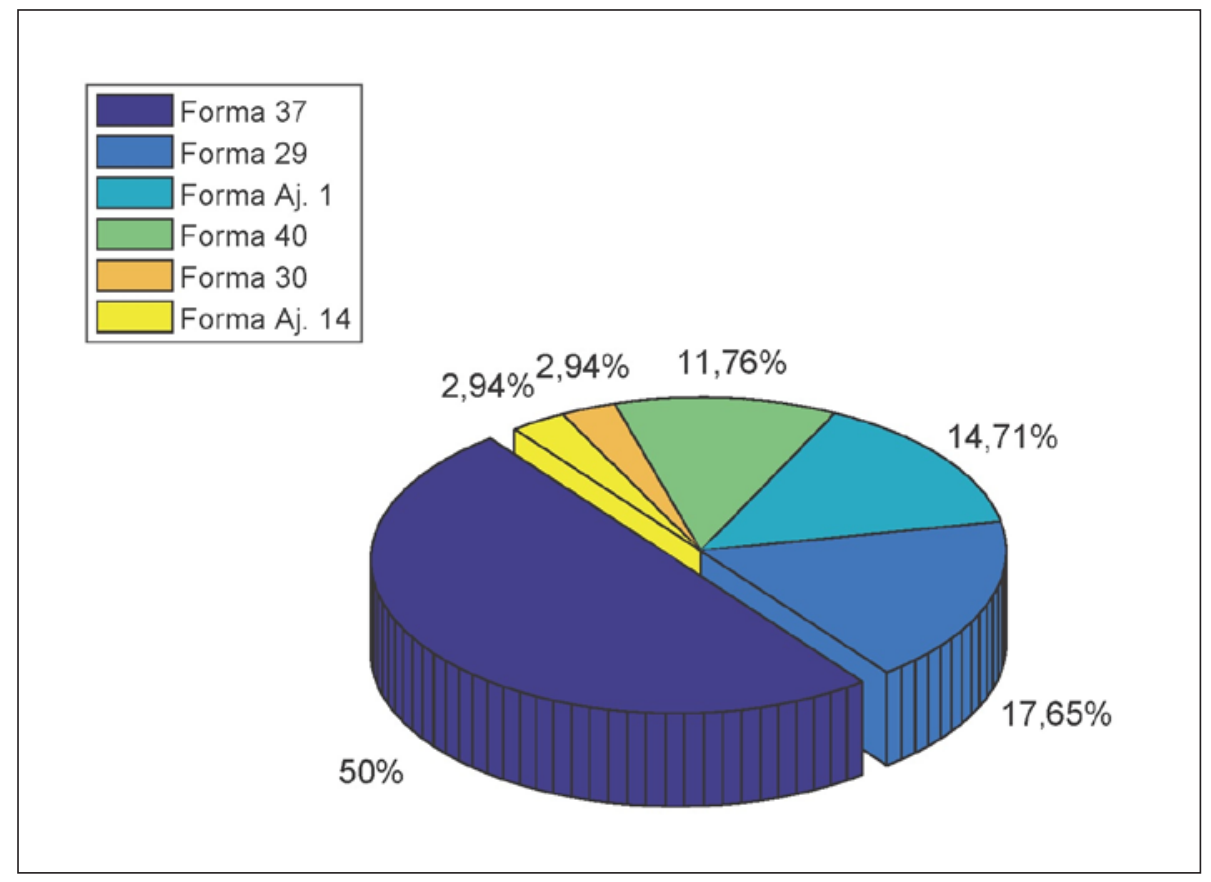

Figura 5. Diagrama de sectores de la distribución de frecuencias de las formas de terra sigillata decorada.

Tabla 1. Análisis de frecuencias de las formas de terra sigillata decorada

\begin{tabular}{|c|r|r|r|}
\hline Forma & Frecuencia & Porcentaje & $\begin{array}{r}\text { Porcentaje } \\
\text { acumulado }\end{array}$ \\
\hline 29 & 6 & $17,65 \%$ & $17,65 \%$ \\
\hline 30 & 1 & $2,94 \%$ & $20,58 \%$ \\
\hline 37 & 17 & $50,00 \%$ & $70,59 \%$ \\
\hline 40 & 4 & $11,76 \%$ & $82,35 \%$ \\
\hline Aj. 1 & 5 & $14,71 \%$ & $97,06 \%$ \\
\hline Aj. 14 & 1 & $2,94 \%$ & $100,00 \%$ \\
\hline & 34 & $100,00 \%$ & \\
\hline
\end{tabular}

que existe una escasa representatividad de la 40 con un 11,8\%, seguida de la 30 (2,9\%) y Aj. 14 (2,9\%). Dentro de las formas que predominan, la 37 y la Aj. 1 están constituidas por un labio fino y un cuerpo semiesférico, y la 29 tiene un borde exvasado y carena. Cabe destacar que las Aj. 1 y 37 están muy relacionadas, al tratarse esta última de una evolución de la primera. $\mathrm{Su}$ forma semiesférica podría estar relacionada con un interés en una mayor capacidad. Esta se caracteriza por presentar unidades mínimas decorativas de carácter variado y/o unidades máximas, especialmente temas de arquería, festón directo, festón invertido y cruciforme. Las formas que aparecen con una frecuencia menor son las denominadas 30, 40, y Aj. 14. La 30 se caracteriza por un labio exvasado y una pared vertical, la 40 presenta un borde plano, generalmente moldurado, con piquera y asas horizontales con forma de lazo, y la $\mathrm{Aj} .14$ posee un labio fino y un perfil semiesférico. La sintaxis decorativa se presenta en dos zonas, constituidas por composiciones en forma de metopas continuas y alternantes, donde se conjugan varias unidades mínimas decorativas y/o unidades máximas decorativas.

En cuanto a las formas de terra sigillata lisas, se han distinguido 23 diferentes dentro del total de las fabricadas en el alfar (actualizadas en Fernández-García y Macías-Fernández 2013b; Roca Roumens 1976). A partir de la distribución de frecuencias (fig. 6 y tab. 2), se observa un predominio de las formas que se caracterizan por un labio fino y un diámetro de borde que oscila entre 6-10 centímetros: 15/17 (8,33\%), 7 (8,33\%), 27 (7,14\%), Aj. $5(7,14 \%), 4(7,14 \%), 35 / 36(5,95 \%)$ y $24 / 25(5,95 \%)$. Cabe destacar que en las manufacturas de las formas 27 y $15 / 17$ se ha evidenciado en el fondo interno de algunos ejemplares la presencia de marcas epigráficas de alfare$\operatorname{ros}(A, A A, A H E, C A H)$. Asimismo en las formas 15/17 y 46 se han documentado marcas anepígrafas materializadas por las marcas de entalle. Las formas con una escasa representatividad son la $37(1,19 \%), \mathrm{Aj} .12$ (1,19\%) y una imitatio elaborada a la manera de la terra sigillata 
Fig. 6. Diagrama de sectores de la distribución de frecuencias de las formas de terra sigillata decorada
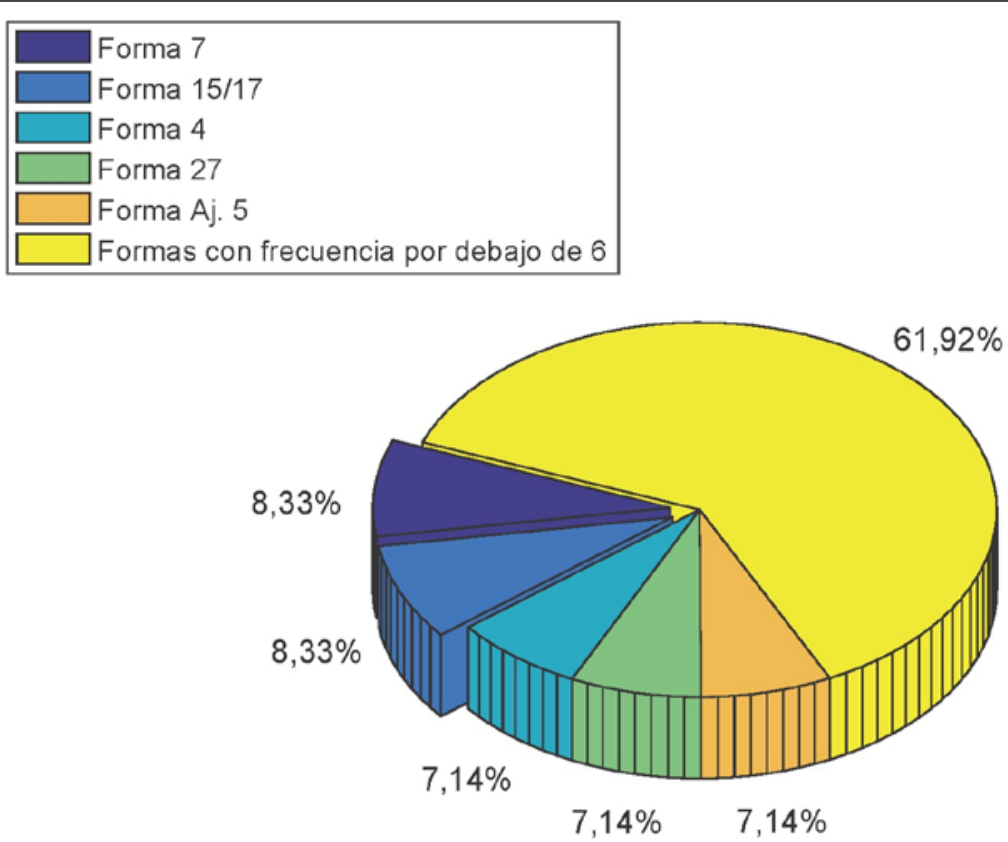

Tabla 2. Análisis de frecuencias de las formas de terra sigillata lisa.

\begin{tabular}{|c|c|c|c|}
\hline Forma & Frecuencia & Porcentaje & $\begin{array}{c}\text { Porcentaje } \\
\text { acumulado }\end{array}$ \\
\hline 2 & 4 & $4,76 \%$ & $4,76 \%$ \\
\hline 4 & 6 & $7,14 \%$ & $11,90 \%$ \\
\hline 7 & 7 & $8,33 \%$ & $20,24 \%$ \\
\hline 13 & 2 & $2,38 \%$ & $22,62 \%$ \\
\hline $15 / 17$ & 7 & $8,33 \%$ & $30,95 \%$ \\
\hline 19 & 4 & $4,76 \% \%$ & $35,71 \%$ \\
\hline 20 & 2 & $2,38 \%$ & $38,10 \%$ \\
\hline $24 / 25$ & 5 & $5,95 \%$ & $44,05 \%$ \\
\hline 27 & 6 & $7,14 \%$ & $51,20 \%$ \\
\hline $35 / 36$ & 5 & $5,95 \%$ & $57,14 \%$ \\
\hline 37 & 1 & $1,19 \%$ & $58,33 \%$ \\
\hline 44 & 3 & $3,57 \%$ & $61,90 \%$ \\
\hline
\end{tabular}

\begin{tabular}{|c|c|r|c|}
\hline Forma & Frecuencia & Porcentaje & $\begin{array}{c}\text { Porcentaje } \\
\text { acumulado }\end{array}$ \\
\hline 57 & 2 & $2,38 \%$ & $64,28 \%$ \\
\hline 59 & 2 & $2,38 \%$ & $66,67 \%$ \\
\hline 72 & 3 & $3,57 \%$ & $70,24 \%$ \\
\hline Aj. 10 & 4 & $4,76 \%$ & $75 \%$ \\
\hline Aj. 6.1 & 5 & $5,95 \%$ & $80,95 \%$ \\
\hline Aj. 6.2 & 2 & $2,38 \%$ & $83,33 \%$ \\
\hline Aj. 12 & 1 & $1,19 \%$ & $84,52 \%$ \\
\hline Aj. 5 & 6 & $7,14 \%$ & $91,67 \%$ \\
\hline Aj. 7 & 2 & $2,38 \%$ & $94,05 \%$ \\
\hline Aj. 9 & 4 & $4,76 \%$ & $98,81 \%$ \\
\hline Hayes 8 A & 1 & $1,19 \%$ & $100,00 \%$ \\
\hline & 84 & $100,00 \%$ & \\
\hline
\end{tabular}

hispánica de la forma de africana A Hayes 8A (1,19\%) que se caracteriza por presentar un borde ancho y liso cerrado con una pared oblicua, con un diámetro de boca ligeramente superior a las formas anteriores; ninguna de las mismas muestra marcas de alfareros.

Otra característica de clasificación relevante es la función a la que estaba destinado el objeto original al que pertenece cada pieza bajo estudio. Su distribución muestra una mayor cantidad de piezas destinadas a contener productos sólidos (fig. 7). 


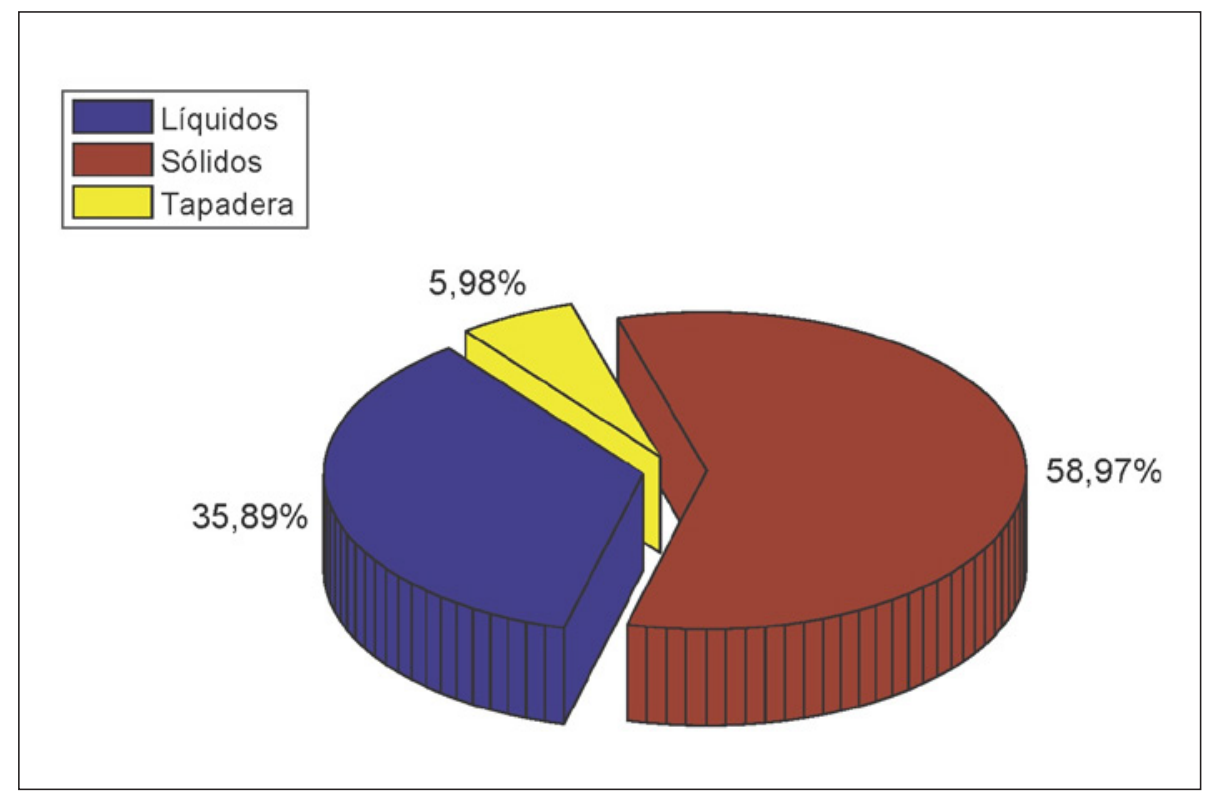

Figura 7. Diagrama de sectores de la distribución de frecuencias de las diferentes funciones de las piezas bajo estudio.

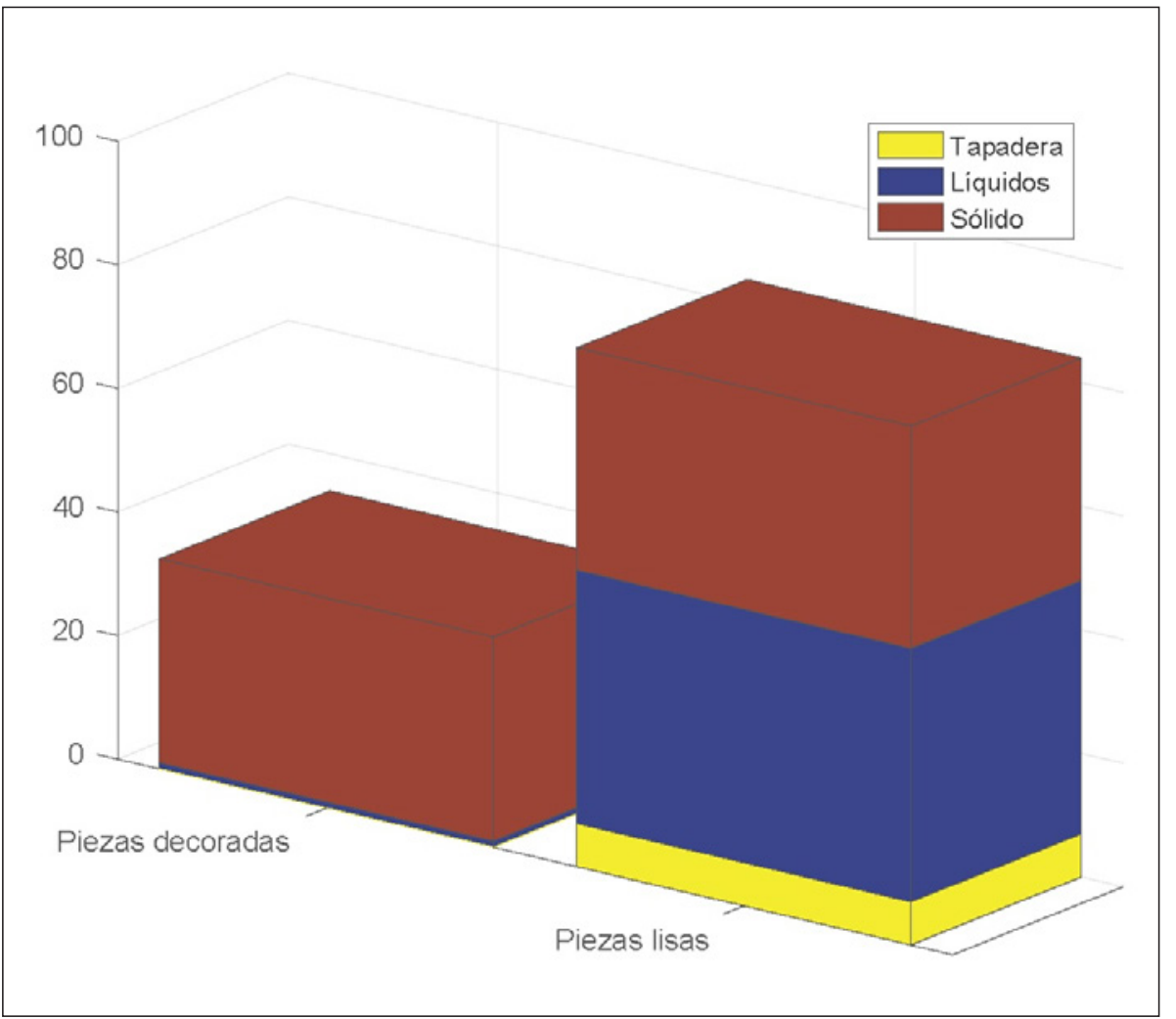

Figura 8. Diagrama de barras compuesto de la distribución de frecuencias de las diferentes funciones de las piezas decoras y lisas.

Por otro lado, la relación entre la clase de cerámica y su función parece clara y merece un estudio comparativo. En el diagrama de barras compuesto (fig. 8) y en la tabla de contingencia (tab. 3) se puede apreciar cómo las piezas decoradas son prácticamente en su totalidad destinadas a contener productos sólidos, mientras que las lisas tienen un uso variado.

Estas diferencias en su distribución muestran una fuerte asociación entre la clase de cerámica y su función. Para contrastar esta asunción se realiza el test de 
Tabla 3. Tabla de contingencia de la distribución de frecuencias de las diferentes funciones de las piezas decoras y lisas.

\begin{tabular}{|l|c|c|c|c|}
\hline \multicolumn{1}{|c|}{ Clase Función } & Líquido & Sólido & Tapadera & $\sum$ \\
\hline Lisa & 41 & 36 & 7 & 84 \\
\hline Decorada & 1 & 33 & 0 & 34 \\
\hline$\sum$ & 42 & 69 & 7 & 118 \\
\hline
\end{tabular}

independencia/asociación entre las variables cualitativas "clase", compuesta por las categorías piezas decoradas y lisas, y "función", compuesta únicamente por las categorías líquido y sólido. Al descartar las piezas cuya función es hacer de tapadera podremos aplicar el contraste exacto de Fisher de tablas 2x2, obteniendo la medida de asociación odds ratio que nos permite cuantificar el grado de asociación. De esta forma, las hipótesis son las siguientes:

- $\mathrm{H}_{0}$ : La función a la que estaba destinada la pieza es independiente de la clase

- $\mathrm{H}_{1}$ : Existe asociación entre la función a la que estaba destinada la pieza y la clase

El valor P obtenido es $9.2016 \times 10^{-8}$, por tanto el contraste es muy significativo, concluyendo que existe una asociación muy alta entre la clase de cerámica y la función de la pieza. Esto se ve reflejado en el valor del odds ratio, 37.5833, que indica que la fracción de las piezas lisas frente a las piezas decoradas es aproximadamente 37 veces mayor si la pieza estaba destinada a contener un producto líquido en lugar de un producto sólido.

\subsection{Análisis de clasificación de las piezas a partir de medidas dimensionales}

En nuestro estudio, una de las asunciones que podemos plantear es que características cualitativas de las piezas, como su clase (lisa o decorada) o función (tarea para la que estaban destinadas), están directamente relacionadas con sus dimensiones físicas. Para estudiar esta posible asociación proponemos realizar una clasificación de las piezas a partir de variables métricas de sus dimensiones físicas. Para ello aplicamos el análisis cluster y, posteriormente, comprobamos si esta ordenación se corresponde con la clasificación de las piezas a partir de características no dimensionales. En nuestro caso nos encontramos con problemas en los datos. Por un lado se tiene la existencia de un número grande de datos faltantes, debido a que la parte que se mide del objeto original no se encuentre en la pieza (diámetro de boca, diámetro de base, etc.). Por otro lado se tiene una falta de comparabilidad entre las piezas, esto es, que aunque podamos medir ciertas características físicas de las piezas, sus valores no son comparables por no estar completas, por ejemplo el peso o la altura. En nuestro caso solo tenemos una variable métrica dimensional comparable en común en un gran número de piezas, el diámetro de la boca, de la que se tiene su valor en 97 de las 118 bajo estudio. A pesar de que con una sola variable dimensional no se pueden extrapolar resultados en cuanto a la posible relación entre atributos (variables cualitativas) y características dimensionales, realizamos el estudio a modo de aproximación. Este consiste en un análisis de clasificación de las piezas de las que se dispone la estimación de su diámetro de boca; posteriormente se compara su posible relación con la clase y la función de las piezas. La técnica utilizada es el método de agrupamiento de las $\mathrm{K}$ medias, el cual realiza particiones de las observaciones (en nuestro caso el diámetro de la boca de las piezas) en $\mathrm{K}$ grupos. Cada pieza pertenecerá al grupo cuyo valor medio sea más cercano. Los resultados suelen mostrase en diagramas de árbol o en mapas de clasificación, aunque los diagramas de árbol son menos intuitivos de interpretar cuando el número de elementos es alto. En este estudio mostramos los resultados en mapas de clasificación que ayudan a determinar de forma visual la posible relación existente. Se debe tener en cuenta que al tener una única variable, esta se representa en ambos ejes para hacer los mapas en dos dimensiones, por tanto las separaciones entre grupos serán líneas diagonales.

Estudio de asociación entre el diámetro de la boca y la versión de clase cerámica de la pieza

Para este análisis se ha realizado la clasificación en dos grupos, para comparar con las versiones lisas y 


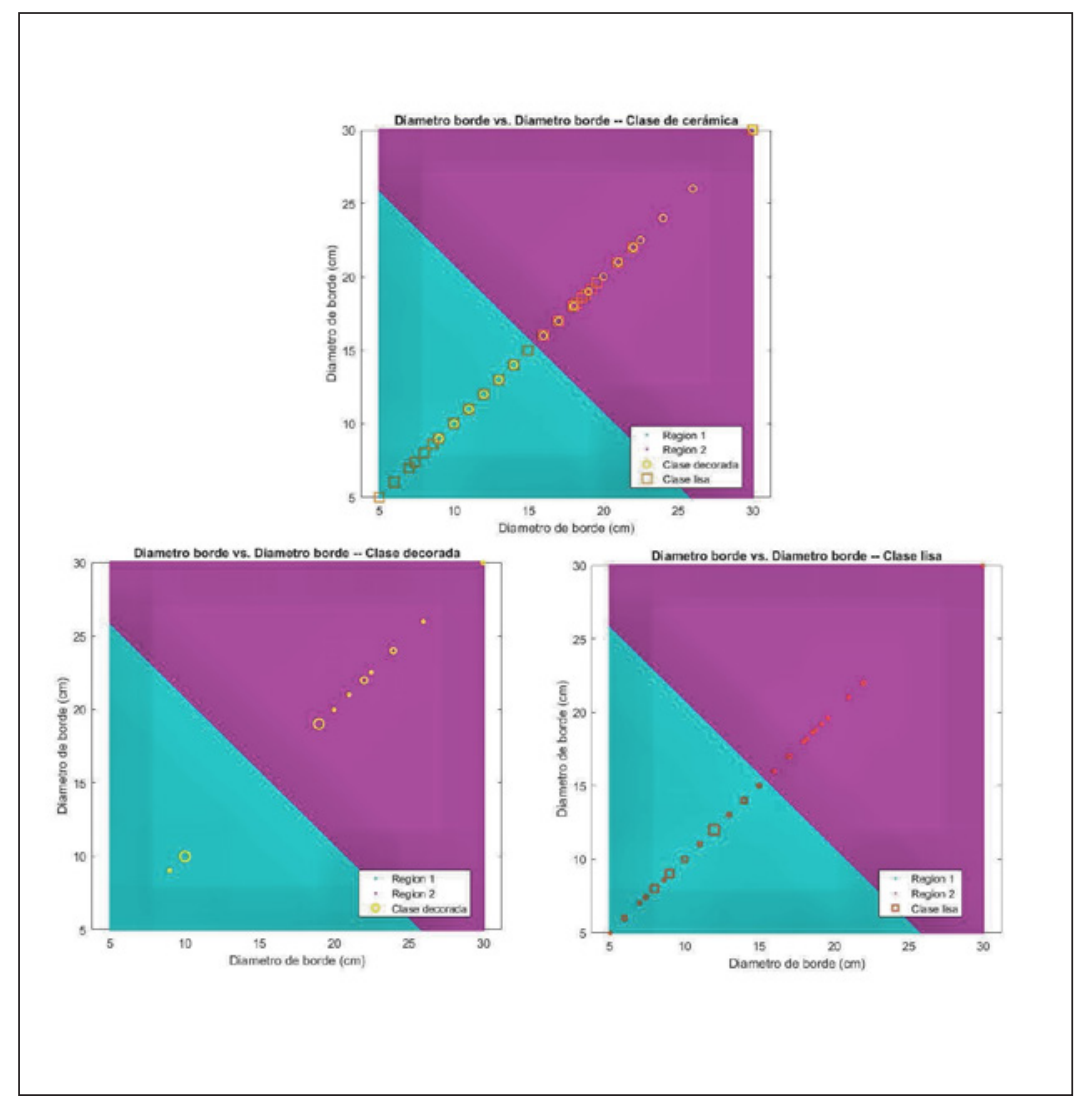

Figura 9. Mapas de clasificación a partir del diámetro de la boca, donde la forma de las marcas representan la clase de cerámica de las piezas y su tamaño la frecuencia. decoradas de piezas. Los resultados obtenidos se muestran en la figura 9. En la imagen superior vemos los dos grupos o regiones obtenidos a partir del algoritmo de las $\mathrm{K}$ medias junto con los diámetros de las piezas, representados por círculos amarillos para las piezas decoradas y cuadrados rojos para las lisas. El problema en este caso es que cada símbolo puede representar más de una pieza. Para solucionar este problema, en la parte inferior tenemos una imagen para las piezas decoradas y otra para las lisas, donde el tamaño de los símbolos indica su grado de representatividad. En estas imágenes vemos cómo las piezas decoradas se localizan principalmente en la región 2, que corresponde a mayores diámetros de la boca, mientras que las lisas aparecen mayormente en la región 1, que representa diámetros más pequeños. Esto podría indicar que las piezas decoradas principalmente pertenecían a menaje de servicio y, por tanto, estaban adaptas al uso colectivo, es decir, requerían una mayor superficie; mientras que en las piezas lisas existe una predominación de piezas de poco diámetro que están relacionadas con menaje de mesa enfocado al uso individual. Esta asociación podría precisarse si se dispusiese de más medidas dimensionales comunes en las piezas.
Estudio de asociación entre el diámetro de la boca y la función de las piezas

En este caso se ha realizado la clasificación en tres grupos, puesto que se tienen tres funciones distintas. Los resultados obtenidos se muestran en la figura 10. En la imagen superior izquierda vemos las tres regiones obtenidas a partir del algoritmo de las $\mathrm{K}$ medias junto con los diámetros de las piezas, representados por círculos azules para las piezas destinadas a contener líquidos, por cuadrados rojos las piezas cuya función es contener productos sólidos, y por asteriscos amarillos las piezas que sirven como tapadera. Al igual que en el caso anterior, para poder visualizar la frecuencia de cada símbolo se muestran las imágenes de cada una de las funciones por separado. Aquí podemos ver cómo las piezas destinadas a contener líquidos y hacer de tapadera están bastante bien clasificadas a partir del diámetro de la boca, mientras que las piezas usadas para contener productos sólidos no se ajustan bien a la clasificación por su función, puesto que se tienen diámetros de diferentes tamaños. En el caso de los líquidos la predominancia de diámetros pequeños debe explicarse 
Figura 10. Mapas de clasificación a partir del diámetro de la boca, la forma de las marcas representan la función de las piezas y su tamaño la frecuencia.
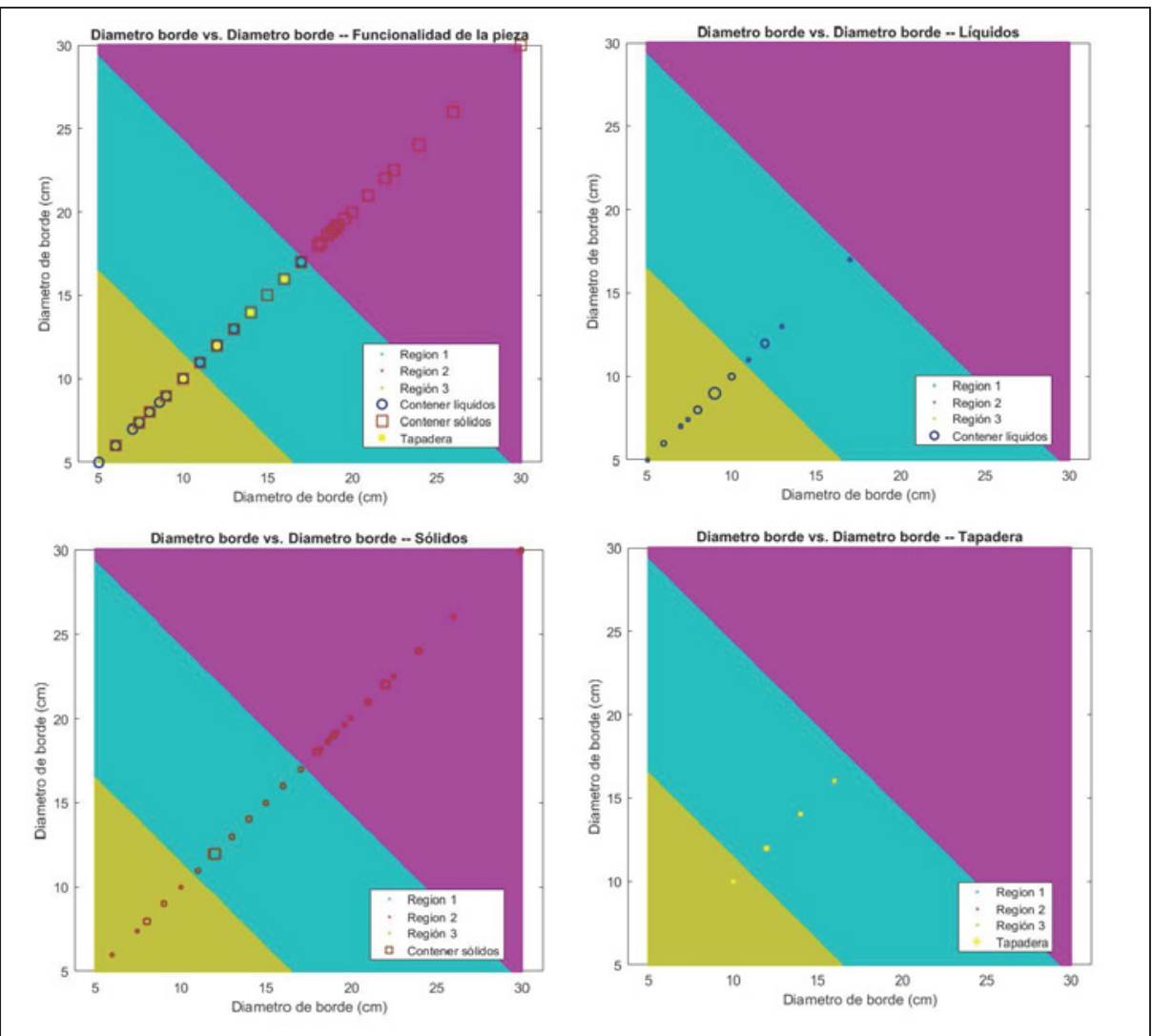

porque se trata de jarras, mientras que en el caso de las tapaderas podría interpretarse que su diámetro de tamaño medio era debido a que se usaban para tapar platos individuales y de esta forma mantener la comida caliente.

\subsection{Estudio de diversidad de la tipología de las piezas}

En esta subsección se analiza el grado de diversidad en la forma de las piezas estudiadas, distinguiendo entre clase cerámica decorada y lisa. Los índices estadísticos de diversidad son muy utilizados en diversas áreas; concretamente, en arqueología han mostrado muy buenos resultados a niveles interpretativos (Kaufman 1998; Stahl 1996). Para realizar las estimaciones de estos índices o parámetros nos encontramos con el problema de disponer, como es usual en este tipo de estudios, de muestras de pequeño tamaño que pueden producir falta de precisión. Cabe señalar que el tamaño muestral será el número de categorías de la variable cualitativa, y que para disminuir el sesgo conviene aplicar metodologías de remuestreo como el Jackknife o el Bootstrap. En nuestro caso nos decantamos por la técnica de Jackknife, en la que se consideran $\mathrm{k}$ submuestras de la muestra original. Lo usual es tomar tantas submuestras como diferentes tipologías existen, en nuestro caso formas de las piezas. Entonces, para un parámetro $(\vartheta)$, se calcula su estimación para la muestra completa y las diferentes submuestras $\left(\vartheta_{y} \vartheta_{i}\right.$, con $i$ $=1, \ldots, k)$ y posteriormente se calculan los pseudovalores mediante la ecuación $\vartheta_{\mathrm{i}}=k \cdot \theta+(\mathrm{k}-1) \cdot \theta_{\mathrm{i}}$. La estimación final del parámetro es el promedio de los pseudovalores obtenidos, $\hat{\theta}=\dot{\theta}$ y el error estándar del parámetro se calcula como $\mathrm{SE}_{\theta}=\Sigma\left[\vartheta_{i}-\vartheta^{2}\right]^{2}(k *(k-$ 1)). En la práctica, asumiendo una distribución normal podemos construir intervalos de confianza y contrastes de hipótesis (Badii et al. 2007) y de esta forma podremos extrapolar resultados muestrales a la población.

\section{Riqueza - Índice Menhinick}

El índice Menhinick es una medida utilizada para estimar la diversidad en distribuciones numéricas de 
Tabla 4. Tabla de los valores estimados para el cálculo del índice de Menhinick mediante la técnica Jackknife.

\begin{tabular}{|c|c|c|c|c|c|c|c|}
\hline Tipo & $\mathrm{S}_{\mathrm{T}}$ & $\mathrm{S}_{1}$ & $\mathrm{~S}_{2}$ & $\mathrm{~S}_{3}$ & $\mathrm{~S}_{4}$ & $\mathrm{~S}_{5}$ & $\mathrm{~S}_{6}$ \\
\hline 29 & 6 & - & 6 & 6 & 6 & 6 & 6 \\
\hline 30 & 1 & 1 & - & 1 & 1 & 1 & 1 \\
\hline 37 & 17 & 17 & 17 & - & 17 & 17 & 17 \\
\hline 40 & 4 & 4 & 4 & 4 & - & 4 & 4 \\
\hline $\mathrm{Aj.} 1$ & 5 & 5 & 5 & 5 & 5 & - & 5 \\
\hline $\mathrm{Aj} .14$ & 1 & 1 & 1 & 1 & 1 & 1 & - \\
\hline $\mathrm{N}$ & 34 & 28 & 33 & 17 & 30 & 29 & 33 \\
\hline $\mathrm{K}$ & 6 & 5 & 5 & 5 & 5 & 5 & 5 \\
\hline$\hat{\theta}_{\mathrm{y}} \hat{\theta}_{\mathrm{i}}$ & 1.0290 & 0.9449 & 0.8704 & 1.2127 & 0.9129 & 0.9285 & 0.8704 \\
\hline$\hat{\vartheta}_{\mathrm{i}}$ & & 1.4494 & 1.8221 & 0.1106 & 1.6096 & 1.5316 & 1.8221 \\
\hline
\end{tabular}

Tabla 5. Estimaciones puntuales y por intervalo de confianza junto con el error estándar de estimación del índice de Menhinick.

\begin{tabular}{|l|c|c|c|}
\hline \multicolumn{1}{|c|}{ Clase } & Valor estimado & Error estándar & Intervalo de confianza \\
\hline Decorada & 1.3909 & 0.4032 & $0.4607-2.3210$ \\
\hline Lisa & 3.7116 & 0.4219 & $2.6793-4.7440$ \\
\hline
\end{tabular}

frecuencias de elementos de un mismo tipo, en función del número de individuos existentes en la muestra analizada (Whittaker 1972). Se calcula como $\mathrm{D}_{M n}=\frac{S}{\sqrt{n}}$, donde $\mathrm{S}$ es el número de diferentes tipologías y $\mathrm{n}$ es el número total de elementos en la muestra. Este índice está acotado inferiormente por 0 y cuanto mayor sea su valor, mayor será la riqueza/diversidad existente en la muestra. Para las piezas decoradas los valores estimados por el método Jackknife se muestran en la tabla 4.

Los resultados muestran que el índice de Menhinick estimado para las piezas lisas, 1.3909, es significativamente mayor que para las piezas decoradas, 3.7116 (ver tab. 5). A partir de estos resultados se entiende que existe una mayor diversidad en cuanto a diferentes tipologías en las piezas lisas. Gracias a la técnica de remuestreo Jackknife podemos realizar afirmaciones sobre la población a partir de los resultados muestrales mediante intervalos de confianza y contrastes de hipótesis. Si nos fijamos en los intervalos de confianza del índice de Menhinick, vemos que el estimado para las piezas lisas está completamente por encima del obtenido para las decoradas, con una confianza del 95\%, con lo que podemos concluir que existe una mayor diversidad en cuanto a diferentes tipologías en las piezas lisas a este nivel de confianza. También es posible contrastar esta afirmación mediante el siguiente test de hipótesis:

$$
\begin{aligned}
& H_{0}: \vartheta(\text { decoradas }) \geq \vartheta \text { (lisas) } \\
& H_{1}: \vartheta(\text { decoradas })<\vartheta(\text { lisas })
\end{aligned}
$$

Al realizar este contraste obtenemos un valor $\mathrm{P}$ igual a $2.6962 \times 10^{-5} \approx 0$, que nos indica que el test es muy significativo y, por tanto, se puede afirmar que la diversidad en la tipología en las piezas lisas es mayor que en las decoradas.

Heterogeneidad - Entropía de Shannon

En 1948, Claude E. Shannon introdujo el concepto de entropía y propuso la medida conocida como entropía de Shannon para cuantificar la incertidumbre existente en un sistema, con el objetivo de estudiar el grado de 
Tabla 6. Tabla de los valores estimados para el cálculo del índice de Menhinick mediante la técnica Jackknife.

\begin{tabular}{|c|c|c|c|c|c|c|c|}
\hline Tipo & $\mathrm{S}_{\mathrm{T}}$ & $\mathrm{S}_{1}$ & $\mathrm{~S}_{2}$ & $\mathrm{~S}_{3}$ & $\mathrm{~S}_{4}$ & $\mathrm{~S}_{5}$ & $\mathrm{~S}_{6}$ \\
\hline 29 & 0.4416 & - & 0.4416 & 0.4416 & 0.4416 & 0.4416 & 0.4416 \\
\hline 30 & 0.1496 & 0.1496 & - & 0.1496 & 0.1496 & 0.1496 & 0.1496 \\
\hline 37 & 0.5000 & 0.5000 & 0.5000 & - & 0.5000 & 0.5000 & 0.5000 \\
\hline 40 & 0.3632 & 0.3632 & 0.3632 & 0.3632 & - & 0.3632 & 0.3632 \\
\hline $\mathrm{Aj.} .1$ & 0.4067 & 0.4067 & 0.4067 & 0.4067 & 0.4067 & - & 0.4067 \\
\hline $\mathrm{Aj.} 14$ & 0.1496 & 0.1496 & 0.1496 & 0.1496 & 0.1496 & 0.1496 & - \\
\hline$\hat{\theta}_{\mathrm{y}} \hat{\theta}_{\mathrm{i}}$ & 0.7779 & 0.7779 & 0.7779 & 0.7779 & 0.7779 & 0.7779 & 0.7779 \\
\hline$\hat{\vartheta}_{\mathrm{i}}$ & - & 1.1674 & 0.6309 & 0.3141 & 1.0353 & 1.1117 & 0.6309 \\
\hline
\end{tabular}

Tabla 7. Estimaciones puntuales y por intervalo de confianza junto con el error estándar de estimación de la entropía de configuración.

\begin{tabular}{|l|c|c|c|}
\hline \multicolumn{1}{|c|}{ Clase } & Valor estimado & Error estándar & Intervalo de confianza \\
\hline Decorada & 0.8150 & 0.1058 & $0.5561-1.0739$ \\
\hline Lisa & 0.9677 & 0.0025 & $0.9616-0.9738$ \\
\hline
\end{tabular}

predictibilidad de ocurrencia de sus elementos. Esta medida ha sido ampliamente utilizada en diversidad de disciplinas científicas tales como Física, Economía, Geología, Biología, etc.; y es conocida en estudios de diversidad como índice de Shannon o de ShannonWeaver. Su expresión de cálculo es

$$
H=-\Sigma p i \log (p i)
$$

donde es la probabilidad de que un elemento elegido al azar sea de tipología $i$, con $i=1, \ldots, S$. Esta medida está acotada inferiormente por $0 \mathrm{y}$ cuanto mayor es su valor, mayor es la heterogeneidad de los datos. En este trabajo se calcula la entropía de configuración que es su versión normalizada por el valor de entropía máxima $H_{\max }=\log (N)$, que corresponde a la distribución equiprobable (en nuestro estudio será el caso en que todas las formas tengan la misma probabilidad de ocurrencia, la misma frecuencia). Por tanto, su valor estará acotado entre 0 y 1 , siendo igual a 1 en el caso en que todas estén igualmente representadas y 0 cuando todas las piezas tengan la misma forma. Tal y como se hizo con el índice de Menhinick, se muestran los cálculos aplicando Jackknife para las piezas decoradas (ver tab. 6). En esta tabla los valores centrales son los valores . Los resultados muestran que la entropía de configuración de Shannon estimada para las piezas lisas es mayor que para las piezas decoradas, aunque el error de las decoradas es significativamente mayor (ver tab. 7).

En esta tabla los valores centrales son los valores . Los resultados muestran que la entropía de configuración de Shannon estimada para las piezas lisas es mayor que para las piezas decoradas, aunque el error es significativamente mayor en las decoradas (ver Tabla 7). A la vista de estos resultados parece que la heterogeneidad es mayor en las piezas lisas que en las decoradas, aunque para poder realizar esta afirmación es necesario interpretar los intervalos de confianza y realizar el contraste de hipótesis. Si nos fijamos en los intervalos de confianza, vemos que el de las piezas lisas no está completamente por encima del de las piezas decoradas (existe un solapamiento entre ambos intervalos); por tanto, no podemos afirmar que la heterogeneidad en cuanto a la tipología sea mayor en las piezas lisas con una confianza del 95\%. Para confirmar esta afirmación realizamos el test de igualdad de medias para contrastar si la heterogeneidad no es la misma en las piezas decoradas y lisas. Ahora las hipótesis son las siguientes:

$$
\begin{aligned}
& H_{0}: \vartheta(\text { decoradas })=\vartheta(\text { lisas }) \\
& H_{1}: \vartheta(\text { decoradas }) \neq \vartheta(\text { lisas })
\end{aligned}
$$


Al realizar este contraste obtenemos un valor $\mathrm{P}$ igual a 0.3226 , que nos indica que no podemos rechazar $\mathrm{H}_{0}$, es decir, no podemos rechazar que la heterogeneidad contenida en la distribución de las tipologías sea diferente entre las clases lisa y decorada.

A partir de los análisis realizados concluimos que las piezas lisas poseen mayor diversidad, como era de esperar por su mayor número de formas morfológicas. En cuanto al grado de homogeneidad en las tipologías, si nos fijamos en la estimación puntual en las piezas lisas podemos ver cómo la estimación de la entropía de configuración es muy cercana a 1. Esto indica que existe un alto grado de homogeneidad entre las tipologías de las piezas lisas, mientras que las piezas decoradas presentan mayor grado de heterogeneidad, lo que se puede interpretar como que existían formas más utilizadas. Esta conclusión no es confirmada ni por el contraste de hipótesis ni por los intervalos de confianza, dado que son muy sensibles a pequeños tamaños muestrales, como es el caso de las piezas decoradas.

\section{DISCUSIÓN Y CONCLUSIÓN}

En este trabajo se describe someramente el estado actual de investigación en el centro de producción de terra sigillata hispánica vinculado a la antigua ciudad de Isturgi (Los Villares de Andújar, Jaén); se realiza un completo registro de documentación de una muestra aleatoria de piezas cerámicas; y se presenta una caracterización de la terra sigillata encontrada en este yacimiento mediante el análisis de las piezas seleccionadas, aplicando diferentes técnicas estadísticas. El estudio estadístico realizado consiste en la descripción de las distribuciones de frecuencias de piezas de acuerdo con las principales características de interés, la clasificación de las piezas bajo estudio atendiendo a la medida dimensional disponible, comparando esta con la obtenida de acuerdo con diferentes características de las piezas, y el cálculo de indicadores de diversidad mediante procedimientos que minimicen el error de estimación.

Al igual que ocurre en otros centros de producción de terra sigillata peninsulares y extrapeninsulares, los resultados muestran un predominio de las piezas lisas, posiblemente debido a la complejidad del proceso productivo de los ejemplares decorados, para los que se necesita de dos instrumentos, punzones y moldes, para hacer posible su manufactura. En cuanto a la morfología, tanto en piezas lisas como decoradas predominan formas semiesféricas, las cuales permiten contener una mayor cantidad del producto (figs. 11 y 12). Ello nos remite a plantearnos una cuestión latente en los estudios actuales acerca de la funcionalidad frente al valor estético. Así mismo, existe una asociación muy fuerte entre las versiones de esta clase cerámica y la función de los ejemplares. En concreto, las piezas lisas eran utilizadas para todo tipo de usos mientras que las piezas decoradas se utilizaban mayoritariamente para contener sólidos. A pesar de tener únicamente una variable dimensional comparable en un número significativamente alto de piezas, el análisis cluster ha mostrado claras relaciones de las dimensiones físicas con las versiones lisas y decoradas y con la función. Estas correspondencias señalan un alto grado de especialización en su producción. Diferenciando entre cerámica lisa y decorada se ha cuantificado la existencia de una mayor diversidad formal en las cerámicas lisas. Esto puede ser interpretado como que las lisas se utilizaban para todo tipo de funciones, mientras que las decoradas eran normalmente usadas en tareas más concretas. Por otro lado, en el caso de las cerámicas decoradas existe mayor heterogeneidad que en el caso de las lisas, lo que indica que posiblemente existían formas cerámicas decoradas predominantes. En relación con esto recordamos el papel predominante de las formas 29 y 37 así como de la Aj. 1. A partir de este estudio se han abierto diferentes líneas de trabajo entre las que destacan:

- Realización de un registro 3D de las piezas que permita tanto aumentar significativamente su divulgación como posibilite tomar medidas dimensionales de forma más precisa e, incluso, el cálculo de medidas que presenten dificultades de forma física como secciones de pared o distancias geodésicas.

- Extender este estudio a otros centros alfareros de terra sigillata peninsulares que amplíen el estudio a mayores cantidades de piezas, para establecer similitudes y diferencias que ayuden a entender mejor a la sociedad romana a través de las estructuras de producción cerámica.

- Ampliar el estudio estadístico incluyendo nuevas medidas dimensionales obtenidas a partir de los modelos 3D de las piezas, que permitan mejorar los resultados de las herramientas estadísticas aplicadas en este trabajo y la aplicación de otras técnicas estadísticas que requieran más características comunes, por ejemplo, un estudio volumétrico.

- Profundizar en la problemática de la selección de la muestra en lo que respecta a características que esta debe tener para garantizar que sea representativa, como pueden ser su selección y su número de piezas. 

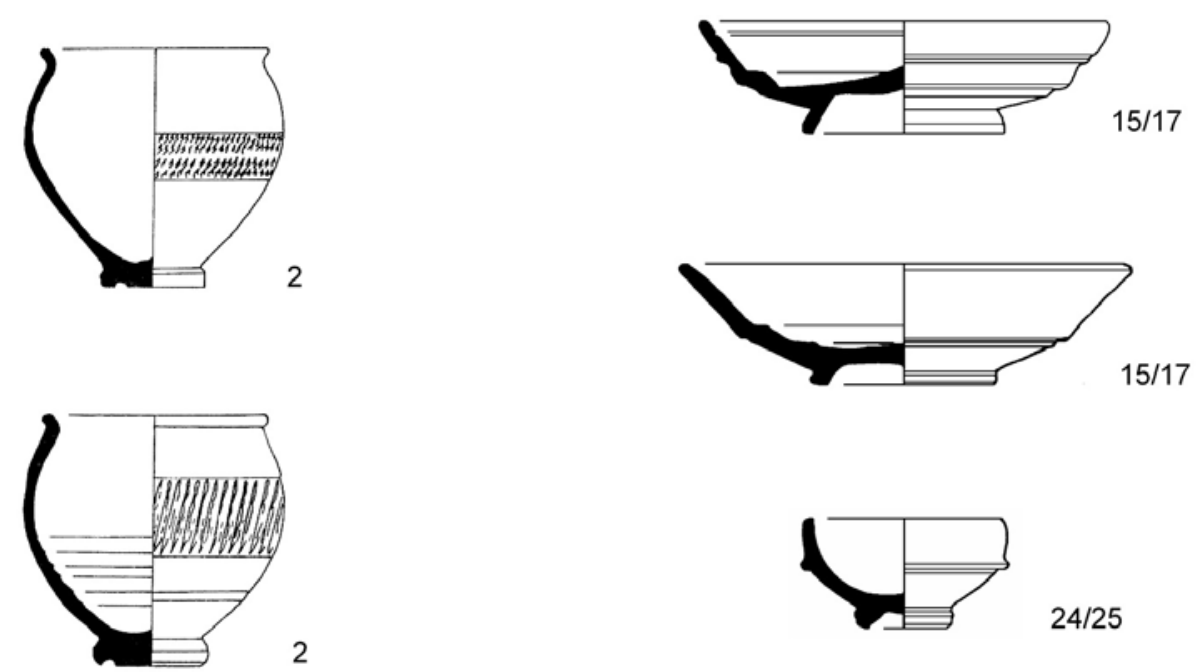

$24 / 25$
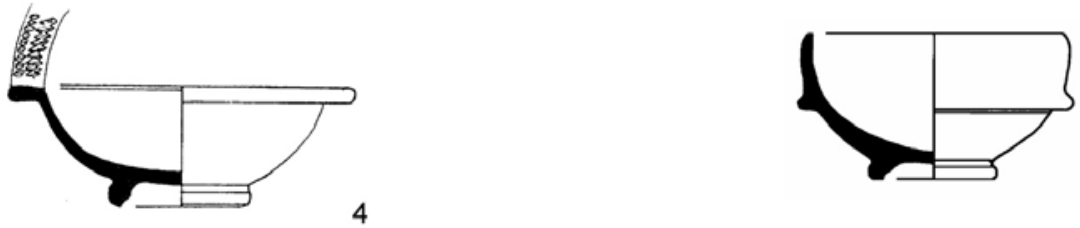

$24 / 25$
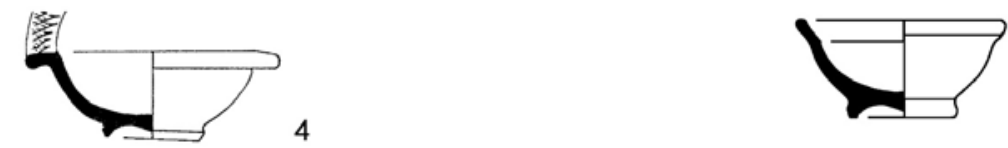

27
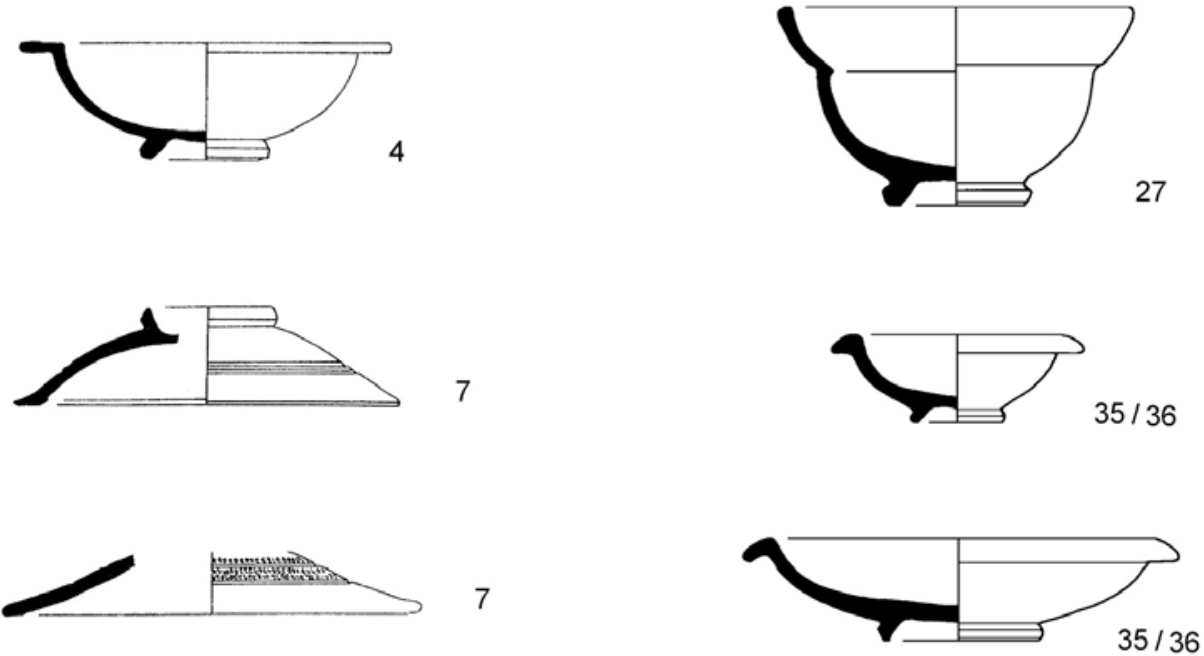

$35 / 36$

Figura 11. Terra Sigillata Hispánica. Formas lisas. Los Villares de Andújar.

ISSN: $1133-4525$ ISSN-e: 2255-3924

SPAL 28.1 (2019): 173-192

http://dx.doi.org/10.12795/spal.2019.i28.08 


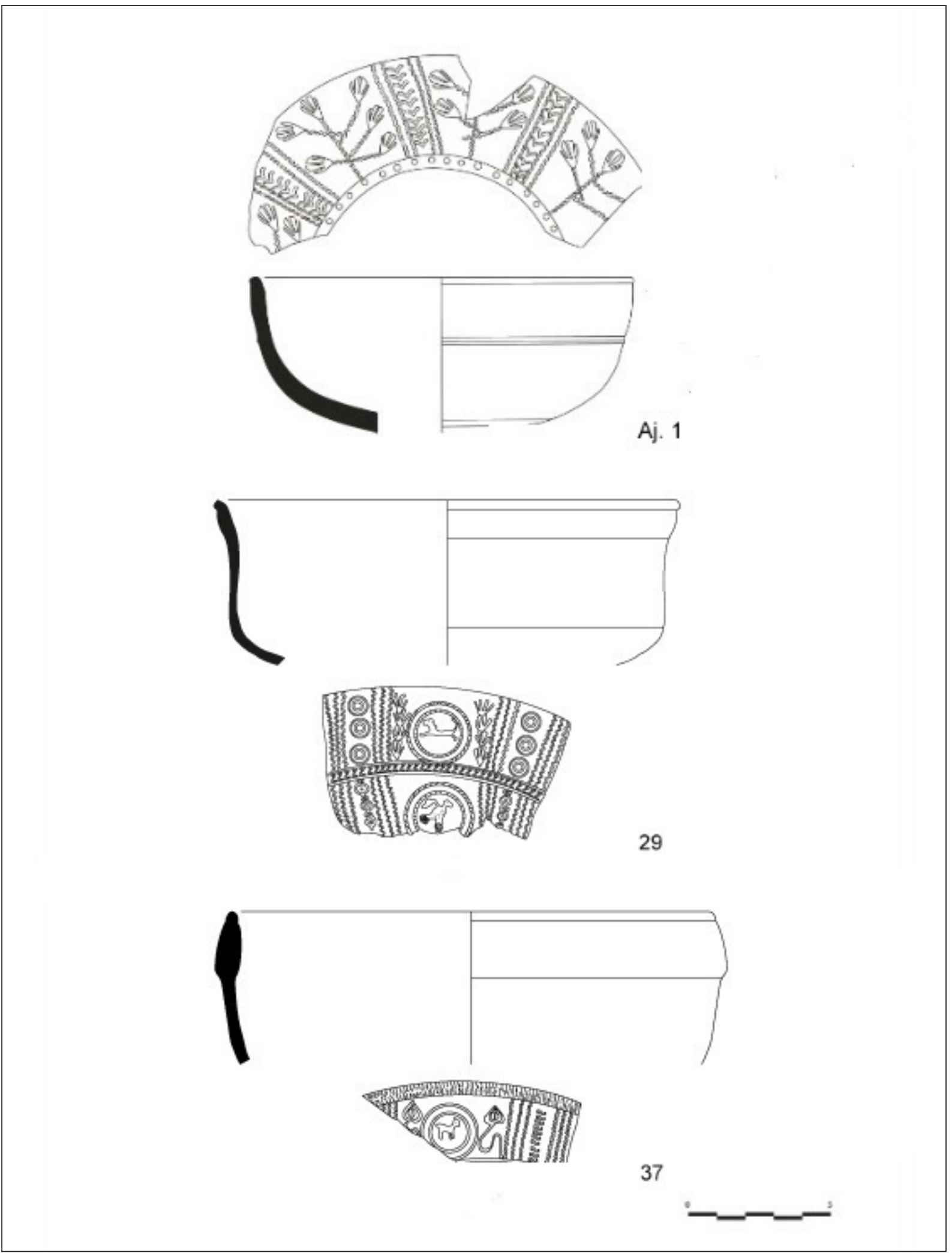

Figura 12. Terra Sigillata Hispánica. Formas decoradas. Los Villares de Andújar. 


\section{Agradecimientos}

El presente trabajo ha contado con el soporte del proyecto de $\mathrm{I}+\mathrm{D}$ "Producción y adquisición de cerámicas finas en el proceso de configuración de las comunidades cívicas de la Bética y la Hispania Meridional durante el Alto Imperio Romano (HAR201675843-P)". Ministerio de Ciencia e Innovación del Gobierno de España. Investigadora Principal María Isabel Fernández-García

\section{BIBLIOGRAFÍA}

Badii, M. H.; Castillo, J.; Wong, A. y Landeros, J. (2007): "Precisión de los índices estadísticas: Técnicas de jacknife \& bootstrap". InnOvaciOnes de NegOciOs 4(1): 63-78.

Cailleux, A. (1981): Notice sur le code des couleurs des sols. París, Boubée.

Esquivel, J. A.; Contreras Cortes, F.; Molina-Gonzalez, F. y Capel Martinez, J. (1991): "Una aplicación de la Teoría de Información al análisis de datos definidos mediante variables cualitativas multi-estado: medidas de similaridad y análisis cluster". Complutum 1: 53-64.

Fernández de Marcos García, C.; Buxeda i Garrigós, J. y Amores, F. (2017): "Nuevos datos sobre la producción de cerámica de cocina y de loza basta de Sevilla en los siglos XV-XVI". Spal 26: 259-280. DOI 10.12795/spal.2017i26.11

Fernández-García, M. I. (2012): "Estructuras de producción y comercialización de los centros de producción de terra sigillata hispánica". La Baetica, Cuadernos de Prehistoria y Arqueología de la Universidad de Granada 22: 379-396.

Fernández-García, M. I. (2013a): Una aproximación a Isturgi romana: El complejo alfarero de Los Villares de Andújar, Jaén, España. Roma, Quasar.

Fernández-García, M. I. (2013b): “Una aproximación a la cronología de los alfares isturgitanos", en M. ${ }^{\mathrm{a}} \mathrm{I}$. Fernández-García (coord.), Una aproximación a Isturgi romana: El complejo alfarero de Los Villares de Andújar, Jaén España: 313-316. Roma, Quasar.

Fernández-García, M. I. (2013c): "Notas acerca de las estructuras de producción de Los Villares de Andújar", en M. ${ }^{a}$ I. Fernández-García (coord.), Una aproximación a Isturgi romana: El complejo alfarero de Los Villares de Andújar, Jaén. España: 6974. Roma, Quasar.

Fernández-García, M. I. (2015): “El centro de producción de terra sigillata hispánica de Los Villares de

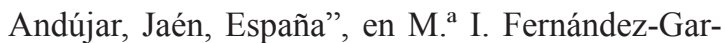
cía, P. Ruiz Montes y M. ${ }^{a}$ V. Peinado Espinosa (eds. científicos), Terra Sigillata Hispánica: 50 años de investigaciones: 57-84. Roma, Quasar.

Fernández-García, M. I. y Macías-Fernández, I. (2013a): "Hacia una estructuración de la producción: las probinas”, en M. ${ }^{a}$ I. Fernández-García (coord.), Una aproximación a Isturgi romana: El complejo alfarero de Los Villares de Andújar, Jaén España: 109-128. Roma, Quasar.

Fernández-García, M. I. y Macías-Fernández, I. (2013b): "Terra sigillata hispánica: producción lisa", en M. ${ }^{a}$ I. Fernández-García (coord.), Una aproximación a Isturgi romana: El complejo alfarero de Los Villares de Andújar, Jaén España: 181196. Roma, Quasar.

Fernández-García, M. I. y Moreno-Alcaide, M. (2013c): "Terra sigillata hispánica: producción de-

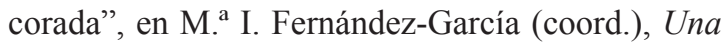
aproximación a Isturgi romana: El complejo alfarero de Los Villares de Andújar, Jaén España: $197-$ 232. Roma, Quasar.

Fernández-Martínez, V.M. (2015): Arqueo-Estadistica: Métodos cuantitativos en Arqueología. Madrid, Alianza.

Hoffman, R. (1988): "The contribution of raptorial birds to patterning in small mammal assemblages". Paleobiology 14(1): 81-90.

Kaufman, D. (1998): "Measuring archeological diversity: an application of the Jackknife technique". American Antiquity 63(1): 73-85.

Moscati,P.(1990): “L'analisi quantitativa nell'archeologia di epoca storica". Archeologia e Calcolatori 1: 39-80.

Orton, C. (1982): Mathematics in archeology. Cambridge, Cambridge University Press.

Orton, C. y Tyers, P. A., (1990): "Statistical analysis of ceramic assemblages". Archeologia e Calcolatori 1: 81-110

Orton, C. y Hughes, M. (2013): Pottery in archeology. Cambridge, Cambridge University Press.

Roca Roumens, M. (1976): Sigillata hispánica producida en Andújar (Jaén). Jaén, Instituto de Estudios Gienenses

Roca Roumens, M. y Fernández-García, M. I. (coords.) (1999): “Terminología y criterios de atribución", en Terra Sigillata Hispánica: centros de fabricación y producción de época altoimperial: 261-267. Jaén, Universidad de Jaén.

Ruiz-Montes, P. (2013): "Del barro al vaso: hornos y procedimientos de cocción”, en M. ${ }^{\mathrm{a}}$ I. Fernández-García (coord.), Una aproximación a Isturgi 
romana: El complejo alfarero de Los Villares de Andújar, Jaén España: 75-90. Roma, Quasar.

Sotomayor, M. (1973): “Centro de producción de sigillata de Andújar (Jaén)", en XII Congreso Nacional de Arqueología: 689-698. Jaén (1971), Zaragoza, Universidad de Zaragoza.

Shennan, S. (1992): Arqueología cuantitativa. Barcelona, Crítica.
Stahl, P. W. (1996): "The recovery and interpretation of microvertebrate bone assemblages from archaeological contexts". Journal of archaeological method and theory 3(1): 31-75.

Whittaker, R. H. (1972): "Evolution and measurement of species diversity”. Taxon 21: 213-251. 